\title{
Sulforaphane suppresses polyinosinic-polycytidylic acid-stimulated release of cytokines, chemokines and MMPs by human corneal fibroblasts
}

\author{
PINGPING LIU ${ }^{1}$, YE LIU ${ }^{2}$, HUI ZHENG ${ }^{1}$, XIAOSHUO ZHENG ${ }^{1}$, XIUXIA YANG ${ }^{1}$, \\ XIAOJING ZHAO ${ }^{1}$, LIN CHEN ${ }^{1}$ and YANG LIU ${ }^{1}$ \\ Departments of ${ }^{1}$ Ophthalmology and ${ }^{2}$ Pathology, The Fifth Affiliated Hospital of Sun Yat-Sen University, \\ Zhuhai, Guangdong 519000, P.R. China
}

Received September 2, 2019; Accepted August 21, 2020

DOI: $10.3892 / \mathrm{mmr} .2020 .11633$

\begin{abstract}
Viral corneal infection is a common cause of visual impairment and blindness. Polyinosinic-polycytidylic acid, or poly(I:C), is similar to viral double-stranded RNA in structure and has been implicated in the release of a variety of cytokines, chemokines and matrix metalloproteinases (MMPs) by corneal fibroblasts. Sulforaphane (SFN) is an isothiocyanate compound found in cruciferous vegetables. The present study investigated the potential effect of SFN on the poly(I:C)-stimulated release of cytokines, chemokines and MMPs in human corneal fibroblasts (HCFs). ELISA showed that SFN was associated with a time- and dose-dependent reduction in poly(I:C)-stimulated production of interleukin (IL)-8, chemoattractant protein-1, IL-6, MMP-1 and MMP-3 by HCFs. Western blot analysis indicated that SFN suppressed the function of poly(I:C) by modulating mitogen-activated protein kinases (MAPKs), including p38 and extracellular signal-regulated kinase (ERK), activator protein-1 (AP-1) component c-Jun and the kinase, Akt, and the phosphorylation

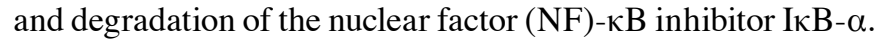
Immunofluorescence analysis revealed that SFN attenuated the production of poly(I:C)-induced nuclear translocation of the NF- $\mathrm{B}$ p65 subunit. Reverse transcription-quantitative PCR analysis revealed that SFN prevented the poly(I:C)-induced upregulation of Toll-like receptor 3 (TLR3) mRNA expression in HCFs. No significant cytotoxic effect of SFN on HCFs was observed. In summary, SFN attenuated the poly(I:C)-induced production of proinflammatory chemokines, cytokines and MMPs by HCFs, by inhibiting TLR3, MAPK (p38 and
\end{abstract}

Correspondence to: Professor Yang Liu, Department of Ophthalmology, The Fifth Affiliated Hospital of Sun Yat-Sen University, 52 Meihuadong Road, Zhuhai, Guangdong 519000, P.R. China

E-mail: yangliu_manu@163.com

Key words: corneal fibroblast, polyinosinic-polycytidylic acid, sulforaphane, viral infection, inflammation
ERK), AP-1, Akt and NF- $\kappa$ B signaling. SFN may therefore be a potential novel treatment for viral corneal infection by limiting immune cell infiltration.

\section{Introduction}

Viral stromal keratitis is an inflammatory disease of the corneal stroma caused by viruses, of which herpes simplex virus type 1 (HSV-1) is the leading cause (1). HSV-1 keratitis can lead to visual impairment and blindness, as a result of corneal scarring, thinning, opacity and neovascularization (1). An epidemiological study in 2012 revealed that the global prevalence of HSV-1 keratitis was estimated to be 1.5 million cases, of which nearly 40,000 new cases of severe monocular visual impairment or blindness occur every year (2). Viral stromal keratitis is not only a simple infectious disease, but a chronic immune disorder, that adversely affects quality of life, even when the infection is not active (3). It is characterized by complex interactions between infiltrating immune cells and corneal intrinsic cells. These interactions induce and sustain an inflammatory response that ultimately lead to corneal damage (4). Current treatment for viral stromal keratitis predominantly consists of the administration of antiviral drugs and topical steroids to control inflammation (5). However, the choice of anti-inflammatory agents is relatively limited. Furthermore, topical glucocorticoids can potentially lead to various complications, such as glaucoma, cataracts and delayed healing (6). The development of reliable anti-inflammatory drugs with fewer side effects is thus, a clinical priority.

The stroma accounts for over $90 \%$ of the corneal thickness, and largely consists of resident keratocytes embedded in a matrix of type I collagen (7). The parallel arrangement of collagen fibers in the extracellular matrix of the corneal stroma is a key determinant of corneal transparency (7). These collagen fibers are produced largely by keratocytes (7). Activated keratocytes, also called corneal fibroblasts, are highly involved in regulating local inflammatory and immune responses to viral infections, through the production of various inflammatory factors, such as IL-6, IL-8 and chemoattractant protein-1 (MCP-1) $(8,9)$. Polyinosinic-polycytidylic acid, or poly( $\mathrm{I}: \mathrm{C})$, is structurally similar to viral double-stranded RNA (dsRNA) and has been 
applied experimentally to investigate the effects of viral infection on various cell types, including microglia, human mucosal epithelial cells and airway epithelial cells (10-12). The interaction of poly(I:C) with Toll-like receptor 3 (TLR3) results in the activation of nuclear factor $(\mathrm{NF})-\kappa \mathrm{B}$ and mitogen-activated protein kinases (MAPKs) (13). These mediate pivotal intracellular signaling pathways underlie the regulation of cell proliferation, differentiation, migration, senescence and apoptosis in response to a variety of extracellular stimuli, including viruses, lipopolysaccharide and certain proinflammatory cytokines, such as IL-1 and TNF- $\alpha(14,15)$. These effects of poly(I:C) on intracellular signaling trigger the release of various proinflammatory factors (13) and matrix metalloproteinases (MMPs) (16) in human corneal fibroblasts (HCFs). The proinflammatory factors, including IL-8, MCP-1 and IL-6, have vital roles in immune cell infiltration and the inflammatory response (17-19). An inflammatory response contributes to the removal of pathogens; however, an excessive infiltration of inflammatory cells and sustained release of cytokines and chemokines can lead to tissue damage, as evidenced by the destruction of corneal structure in viral stromal keratitis (20). The release of MMPs, particularly MMP-1 and MMP-3, has been significantly associated with degradation of the corneal stromal matrix and corneal ulceration in viral stromal keratitis (21).

Sulforaphane (1-isothiocyanate-4-methanesulfonyl butane; SFN) is a natural plant compound found in cruciferous plants, particularly in broccoli. SFN is derived from the hydrolysis of its precursor, glucosinolate (a reaction catalyzed by the enzyme myrosinase) (22). It is well-known that SFN is a natural antioxidant, and has anti-cancer (23) and antiinflammatory $(24,25)$ effects. It has been shown that SFN inhibits the proinflammatory action of lipopolysaccharides on microglia through the downregulation of the NF- $\mathrm{kB}$ and MAPK signaling pathways (26). Furthermore, in vitro and in vivo studies have shown that SFN can suppress the occurrence and progression of ocular diseases, such as cataracts (27), age-related macular degeneration (28) and Fuchs' corneal endothelial dystrophy (29), which were associated with its potential antioxidant effects. However, the possible effect of SFN on ocular inflammatory diseases is unclear. The present study investigated the potential anti-inflammatory effects of SFN on the release of cytokines, chemokines, and MMPs in HCFs stimulated by poly(I:C).

\section{Materials and methods}

Materials. Fetal bovine serum (FBS), trypsin-EDTA and Eagle's minimum essential medium (MEM) were purchased from Gibco (Thermo Fisher Scientific, Inc.). Cell culture dishes, 24-well plates and flasks were obtained from Corning Inc. Sigma-Aldrich (Merck KGaA) supplied the SFN; and poly(I:C) was provided by InvivoGen. ELISA kits for IL-8 (cat. no. Q8000B), MCP-1 (cat. no. DCP00) and IL-6 (cat. no. Q6000B), were obtained from R\&D Systems, Inc., while the kits for MMP-1 (cat. no. ab215083) and MMP-3 (cat. no. ab269371) were obtained from Abcam. The following antibodies were obtained from Cell Signaling Technology, Inc.: Anti-JNK (cat. no. 9252), phosphorylated (p)JNK (cat. no. 9251), IкB- $\alpha$ (cat. no. 9242), p-IкB- $\alpha$ (cat. no. 2859),
ERK (cat.no.9102),p-ERK (cat.no.9106), c-Jun (cat.no.9165), p-c-Jun (cat.no.9164),p38 MAPK (cat.no. 9212),p-p38 MAPK (cat. no. 9211), Akt (cat. no. 9272) and p-Akt (cat. no. 9271). The antibody against GAPDH (cat. no. 60004-1-Ig) was purchased from ProteinTech Group, Inc. Goat anti-mouse horseradish peroxidase (HRP)-conjugated antibody (cat. no. A0216), rabbit immunoglobulin G (cat. no. A0208), bovine serum albumin and enhanced chemiluminescence (ECL) reagents were purchased from Beyotime Institute of Biotechnology. The primary antibody against NF- $\kappa \mathrm{B}$ p65 (cat. no. sc-8008) was purchased from Santa Cruz Biotechnology, Inc. Molecular Probes (Thermo Fisher Scientific, Inc.) supplied the 4',6-diamidino-2-phenylindole (DAPI) and Alexa Fluor 488-labeled donkey antibodies to mouse immunoglobulin G (cat. no. A-21202). The RNAprep pure kit (cat. no. DP430) was supplied by Tiangen Biotech Co., Ltd. A non-radioactive cytotoxicity assay kit for lactate dehydrogenase (LDH) was purchased from Promega Corporation. Endotoxin minimization was performed for all media and reagents used for cell culture.

Cell culture and treatment with SFN. Human keratocytes (cat. no. 6520) were purchased from ScienCell Research Laboratories, Inc. The cultured keratocytes (activated keratocytes), also called corneal fibroblasts, were maintained in MEM supplemented with $10 \% \mathrm{FBS}$ at $37^{\circ} \mathrm{C}$ in a humidified incubator with $5 \% \mathrm{CO}_{2}$. After four to seven passages, $\mathrm{HCF}$ used for subsequent experimentation were harvested at the subconfluent stage, and further seeded into 24-well plates ( $3 \times 10^{4}$ cells/well) or $60-\mathrm{mm}$ culture dishes $\left(5 \times 10^{5}\right.$ cells/dish). When the HCFs obtained confluence, the previous media was discarded, and serum-free culture media was added for an additional day. Poly(I:C) $(3 \mu \mathrm{g} / \mathrm{ml})$ was added to the medium as a mimic of viral dsRNA, alongside various concentrations of $\operatorname{SFN}(1,2,5$ or $10 \mu \mathrm{M})$ as interventions.

Assays of $I L-8, M C P-1, I L-6, M M P-1$ and $M M P-3$. Serum-deprived corneal fibroblasts were incubated in the serum-free MEM with or without SFN $(10 \mu \mathrm{M})$ for $24 \mathrm{~h}$, and then maintained in the same buffer containing poly(I:C) $(3 \mu \mathrm{g} / \mathrm{ml})$ for another 12, 24, 36 and $48 \mathrm{~h}$. Cell supernatant fluid was obtained following centrifugation at $120 \mathrm{x}$ g for 5 min at $4^{\circ} \mathrm{C}$, and frozen at $-80^{\circ} \mathrm{C}$ for subsequent assessments of IL-8, MCP-1, IL-6, MMP-1 and MMP-3 with ELISA kits. Following exposure to trypsin-EDTA, the cells were isolated from the culture plates, stained with trypan blue for $3 \mathrm{~min}$ at room temperature and further counted using a hemocytometer. As counting of the cells and morphology were not influenced by exposure to SFN or poly(I:C), the measurements of these proteins in the culture supernatants were normalized by cell number.

Western blot analysis. The protein expression levels of Akt, c-Jun, MAPKs and IкB- $\alpha$ in the HCFs were detected using western blot analysis. During the first $24 \mathrm{~h}$, cells were maintained in MEM with $0.5 \%$ FBS, and then cultured in serum-free medium for another $24 \mathrm{~h}$. The serum-deprived cells were further incubated in serum-free MEM with or without SFN $(10 \mu \mathrm{M})$ for $24 \mathrm{~h}$, and were incubated in the same solution with or without poly(I:C) $(3 \mu \mathrm{g} / \mathrm{ml})$, as previously described (16) for 
an additional $30 \mathrm{~min}$ (for Akt) or $90 \mathrm{~min}$ (for MAPKs, IкB- $\alpha$ and c-Jun). The cells were washed twice with ice-cold PBS and lysed in a solution containing the following: 1\% protease inhibitor cocktail; $100 \mathrm{mM} \mathrm{NaCl} ; 1 \%$ Nonidet P-40; $10 \mathrm{mM}$ $\mathrm{MgCl}_{2} ; 1 \mathrm{mM}$ dithiothreitol; $50 \mathrm{mM}$ Tris- $\mathrm{HCl}$ (pH 7.4); and $1 \mathrm{mM}$ phenylmethylsulfonyl fluoride. Following centrifugation $\left(120 \mathrm{x} \mathrm{g}\right.$, for $10 \mathrm{~min}$ at $\left.4^{\circ} \mathrm{C}\right)$, the cell lysates were collected to measure the protein concentration using the Bradford method. The total protein $(10 \mu \mathrm{g})$ was first stacked with $10 \%$ SDS-PAGE gels and then resolved with $6 \%$ gels. Subsequently, the proteins were transferred onto polyvinylidene difluoride membranes $(0.45 \mu \mathrm{m})$, then blocked in a mixture containing $5 \%$ skimmed milk in TBS-Tween-20, following which the membranes were incubated overnight at $4^{\circ} \mathrm{C}$, with the primary antibodies (all at 1:1,000) diluted in the blocking buffer. The following day, the membranes were washed using a mixture of $20 \mathrm{mM}$ Tris- $\mathrm{HCl}$ (pH 7.4) and $0.1 \%$ Tween-20, and incubated with the secondary antibody conjugated to HRP (dilution 1:3,000) at room temperature for $1 \mathrm{~h}$. The proteins were imaged immediately with a Tanon-5200 Multi-imaging System following incubation with ECL solutions (Tanon Science and Technology Co., Ltd.).

Immunofluorescence staining. HCFs were maintained for $24 \mathrm{~h}$ in MEM containing $0.5 \%$ FBS, then serum-free media for an additional $24 \mathrm{~h}$. This was followed by another $24 \mathrm{~h}$ with or without SFN $(10 \mu \mathrm{M})$ in serum-free MEM, and an additional $90 \mathrm{~min}$ in the same solution with or without poly(I:C) ( $3 \mu \mathrm{g} / \mathrm{ml}$ ). The cells were fixed with $4 \%$ paraformaldehyde at room temperature for $15 \mathrm{~min}$ before being permeabilized with $0.2 \%$ Triton X-100 for $15 \mathrm{~min}$ at room temperature. Between each step, the cells were washed with PBS. Non-specific adsorption of antibodies was blocked by adding $3 \%$ bovine serum albumin for $15 \mathrm{~min}$ at room temperature. The cells were then incubated with a mouse monoclonal antibody (anti-NF- $\mathrm{B} ; 1: 50$ ) at room temperature for $1 \mathrm{~h}$. Subsequently, the cells were further incubated for $1 \mathrm{~h}$ at room temperature with Alexa Fluor 488-conjugated secondary antibodies (diluted 1:500) and DAPI. Finally, the images were obtained using a fluorescence microscope (Zeiss AG).

Reverse transcription-quantitative PCR (RT-qPCR) analysis. Serum-deprived HCFs were incubated first for $24 \mathrm{~h}$ with or without SFN $(10 \mu \mathrm{M})$ in serum-free MEM, and then for an additional $4 \mathrm{~h}$ with or without poly(I:C) $(3 \mu \mathrm{g} / \mathrm{ml})$ in the same medium. Total RNA was isolated from the cells using the RNAprep pure kit and subjected to RT-qPCR analysis, as previously described (30). The sequences of the PCR primers were as follows (30): TLR3 sense, 5'-CGCCAACTTCAC AAGGTA-3' and antisense, 5'-GGAAGCCAAGCAAAG GAA-3'; hypoxanthine phosphoribosyltransferase 1 (HPRT1) sense, 5'-AGATGGTCAAGGTCGCAAGC-3'; and antisense, 5'-CATATCCTACAACAAACTTGTCTGGAA-3'. PCR was performed with an ABI Prism 7900 Sequence Detection system (Applied Biosystems; Thermo Fisher Scientific, Inc.). The following thermocycling conditions were used: Denaturation at $95^{\circ} \mathrm{C}$ for $15 \mathrm{sec}$, annealing at $60^{\circ} \mathrm{C}$ for $15 \mathrm{sec}$ followed by elongation at $60^{\circ} \mathrm{C}$ for $15 \mathrm{sec}$. The qPCR results, recorded as threshold cycle numbers $(\mathrm{Cq})$, were calculated using the $2^{-\Delta \Delta \mathrm{Cq}}$ method (31) with normalization against HPRT1 mRNA as an internal control.

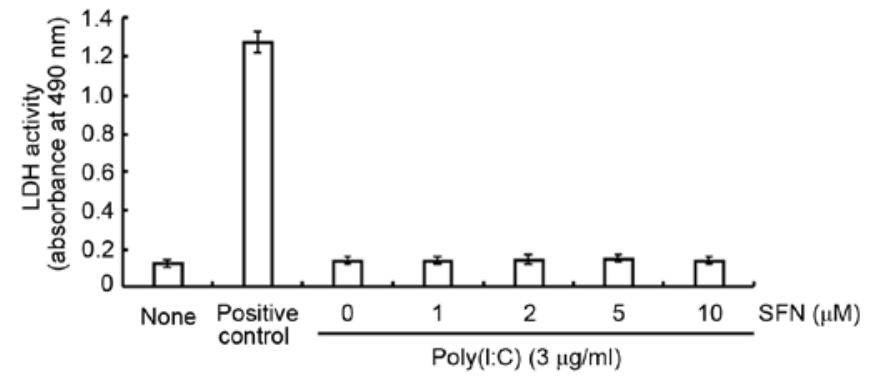

Figure 1. Cytotoxic effect of SFN in the HCFs. Serum-deprived HCFs were incubated with the corresponding doses of SFN for $24 \mathrm{~h}$, then with poly(I:C) $(3 \mu \mathrm{g} / \mathrm{ml})$ for another $24 \mathrm{~h}$. The release of LDH was detected using an assay. Data are shown as the mean \pm standard deviation, averaged from triplicates and was repeated three times with similar results. SFN, sulforaphane; HCF human corneal fibroblasts; poly(I:C), polyinosinic-polycytidylic acid; LDH, lactate dehydrogenase.

LDH (cytotoxicity) assay. A non-radioactive cytotoxicity assay was used to assess the production of LDH by cultured corneal fibroblasts. Portions $(50 \mu \mathrm{l})$ of the same culture supernatants, used for the assessment of IL-8, MCP-1 and IL-8, were transferred to a 96-well flat-bottom plate, then mixed with $50 \mu \mathrm{l}$ CytoTox reagent. The plate was covered with an opaque box to prevent light exposure for $30 \mathrm{~min}$ at room temperature, then stop solution was added to each well $(50 \mu \mathrm{l})$. The LDH assay was performed at an optical density of $490 \mathrm{~nm}$ using a microplate reader (Bio-Rad Laboratories, Inc.). As a positive control, cells were lysed prior to the assay with a lysis solution containing detergent provided with the assay kit.

Statistical analysis. Data for each group were derived from at least three independent samples, and all sampling was repeated three times in the experimental groups. All statistical analyses were performed using SPSS software (version 20.0; IBM Corp.). Descriptive results are expressed as the mean \pm standard deviation and were compared with an unpaired two-tailed t-test or one-way analysis of variance, followed by a Tukey's post hoc test. $\mathrm{P}<0.05$ was considered to indicate a statistically significant difference.

\section{Results}

Cytotoxicity of SFN in HCFs. To examine whether SFN is cytotoxic to HCFs, the effect of SFN on the release of LDH was investigated. SFN at concentrations of $1,2,5$ or $10 \mu \mathrm{M}$ had no significant effect on LDH release in the presence of poly(I:C) at $3 \mu \mathrm{g} / \mathrm{ml}$ (Fig. 1), which suggests a lack of cytotoxicity.

Effects of SFN on the poly(I:C)-induced release of $I L-8$, MCP-1 and IL- 6 by HCFs. Exposure of HCFs to various concentrations of SFN for $24 \mathrm{~h}$ prior to incubation with poly(I:C) $(3 \mu \mathrm{g} / \mathrm{ml})$ for $24 \mathrm{~h}$ attenuated the secretion of IL-6 and IL- 8 in a dose-dependent manner and that of MCP-1 at 5 and $10 \mu \mathrm{M} \mathrm{SFN}$ (Fig. 2A). The inhibitory effects of SFN were statistically significant at concentrations of $\geq 2 \mu \mathrm{M}$ for IL-6 and IL-8 and at $\geq 5 \mu \mathrm{M}$ for MCP-1 compared with $0 \mu \mathrm{M}$ SFN. Furthermore, SFN (10 $\mu \mathrm{M})$ attenuated the poly(I:C)-induced release of these inflammatory mediators in a time-dependent manner (Fig. 2B), with each inhibitory effect being statistically 

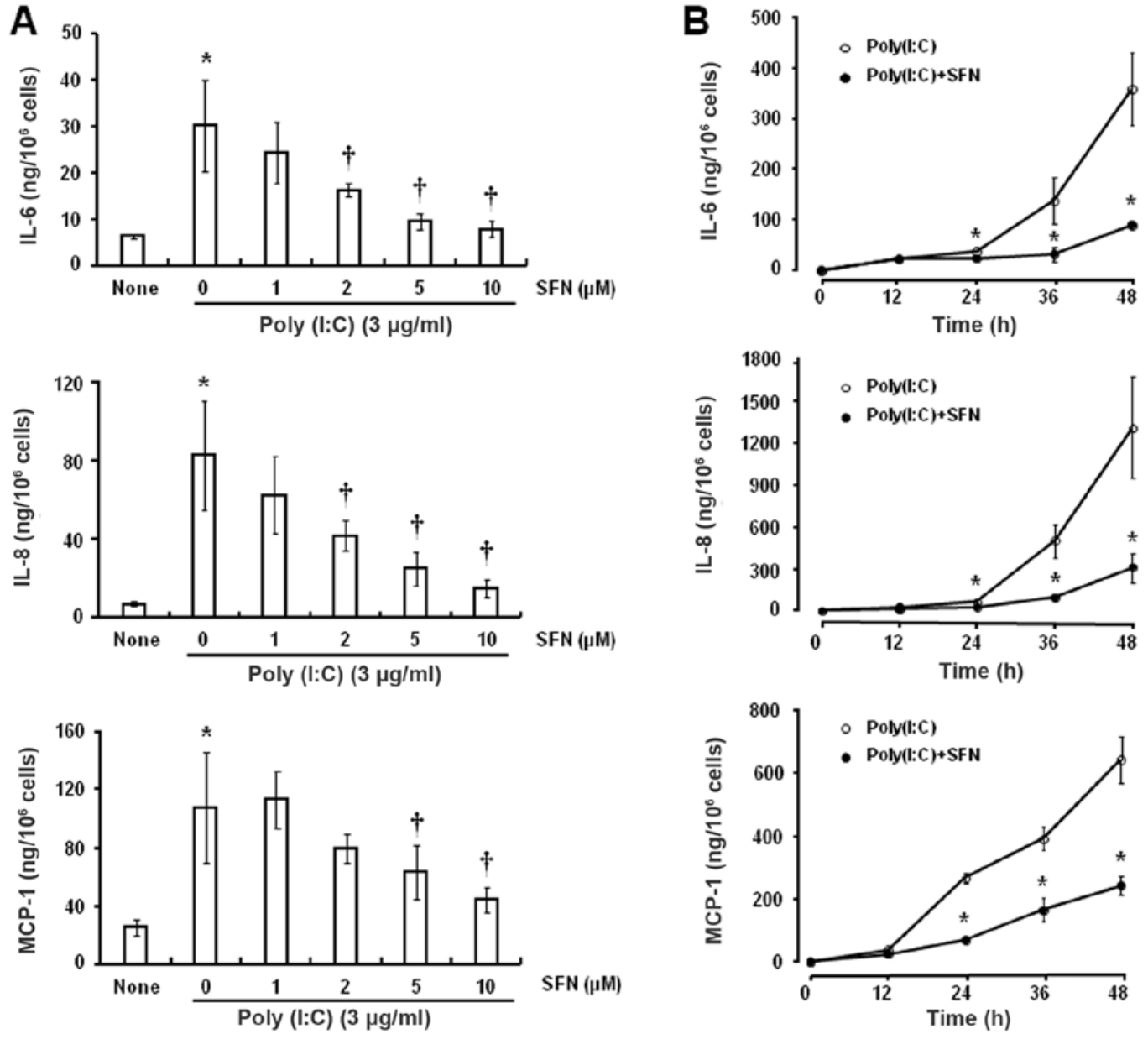

Figure 2. Inhibitory effects of SFN on the poly(I:C)-induced release of IL-6, IL-8 and MCP-1 by the HCFs. (A) Serum-deprived HCFs were treated with the corresponding concentrations of SFN for $24 \mathrm{~h}$, then poly(I:C) $(3 \mu \mathrm{g} / \mathrm{ml})$ was added for another $24 \mathrm{~h}$. The results were assessed using ELISA. ${ }^{*} \mathrm{P}<0.05 \mathrm{compared}$ with the control group (None). ${ }^{\dagger} \mathrm{P}<0.05$ compared with that in the cells exposed to poly(I:C) alone. (B) Serum-deprived HCFs were incubated for $24 \mathrm{~h}$ with (solid circles) or without (open circles) SFN $(10 \mu \mathrm{M})$, then incubated for the specified time durations with poly(I:C) $(3 \mu \mathrm{g} / \mathrm{ml})$. The release of these inflammatory factors was measured using ELISA. ${ }^{*} \mathrm{P}<0.05$ compared with the cells incubated with poly(I:C) alone. SFN, sulforaphane; MCP-1, chemoattractant protein-1; poly(I:C), polyinosinic-polycytidylic acid; HCF, human corneal fibroblasts; IL, interleukin.

significant following exposure to poly(I:C) for $\geq 24 \mathrm{~h}$ compared with the respective times in the group without SFN treatment.

Effects of SFN on poly(I:C)-induced changes in MMP production by HCFs. Poly(I:C) increased the release of MMP-1 and MMP-3 by HCFs, which was sensitive to inhibition by SFN, in a dose-dependent manner (Fig. 3A). The inhibitory effects of SFN were statistically significant at concentrations $\geq 1 \mu \mathrm{M}$ compared with $0 \mu \mathrm{M}$ SFN. In addition, SFN $(10 \mu \mathrm{M})$ significantly attenuated the poly(I:C)-induced release of MMP-1 and MMP-3 after exposure to poly(I:C) for 36 and $48 \mathrm{~h}$ compared with the respective times in the group without SFN treatment (Fig. 3B).

Effect of SFN on poly(I:C)-induced expression of TLR3 in HCFs. RT-qPCR analysis revealed that incubation of serum-deprived HCFs with poly(I:C) $(3 \mu \mathrm{g} / \mathrm{ml})$ for $4 \mathrm{~h}$ induced significant upregulation of TLR3 mRNA expression level (Fig. 4). Furthermore, prior exposure of the cells to SFN $(10 \mu \mathrm{M})$ for $24 \mathrm{~h}$ prevented this effect of poly(I:C). SFN also reduced the basal abundance of TLR3 mRNA in the cells (Fig. 4).
Effects of SFN on poly(I:C)-associated activation of MAPK and AP-1 protein expression level by HCFs. Western blot analysis showed that exposure of HCFs to poly(I:C) for $90 \mathrm{~min}$ increased the expression level of the phosphorylated forms of ERK, p38, c-Jun $\mathrm{NH}_{2}$-terminal kinase (JNK) and c-Jun; however, there was no marked effect on the total amounts of these proteins (Fig. 5), which indicated that poly(I:C) activated the MAPK and AP-1 signal pathways. SFN $(10 \mu \mathrm{M})$ inhibited the poly(I:C)-induced phosphorylation of ERK (Fig. 5A), p38 (Fig. 5B) and c-Jun (Fig. 5D), however, there was no marked effect on that of JNK (Fig. 5C).

Effects of SFN on poly(I:C)-mediated activation of I $\kappa$ B- $\alpha$ and $N F-\kappa B$ by HCFs. Western blot analysis revealed that SFN $(10 \mu \mathrm{M})$ suppressed the poly(I:C)-induced phosphorylation of the NF- $\kappa \mathrm{B}$ inhibitor I $\kappa \mathrm{B}-\alpha$ in HCFs (Fig. 6A). Furthermore, the immunofluorescence analysis showed that, whereas the p65 subunit of NF- $\kappa B$ was localized predominantly in the cytoplasm of HCFs under control conditions, it was localized to the nucleus following exposure of the cells to poly(I:C) for $90 \mathrm{~min}$, and the effect of poly(I:C) was partially prevented by SFN (Fig. 6B). Thus, these results indicated that SFN 
A
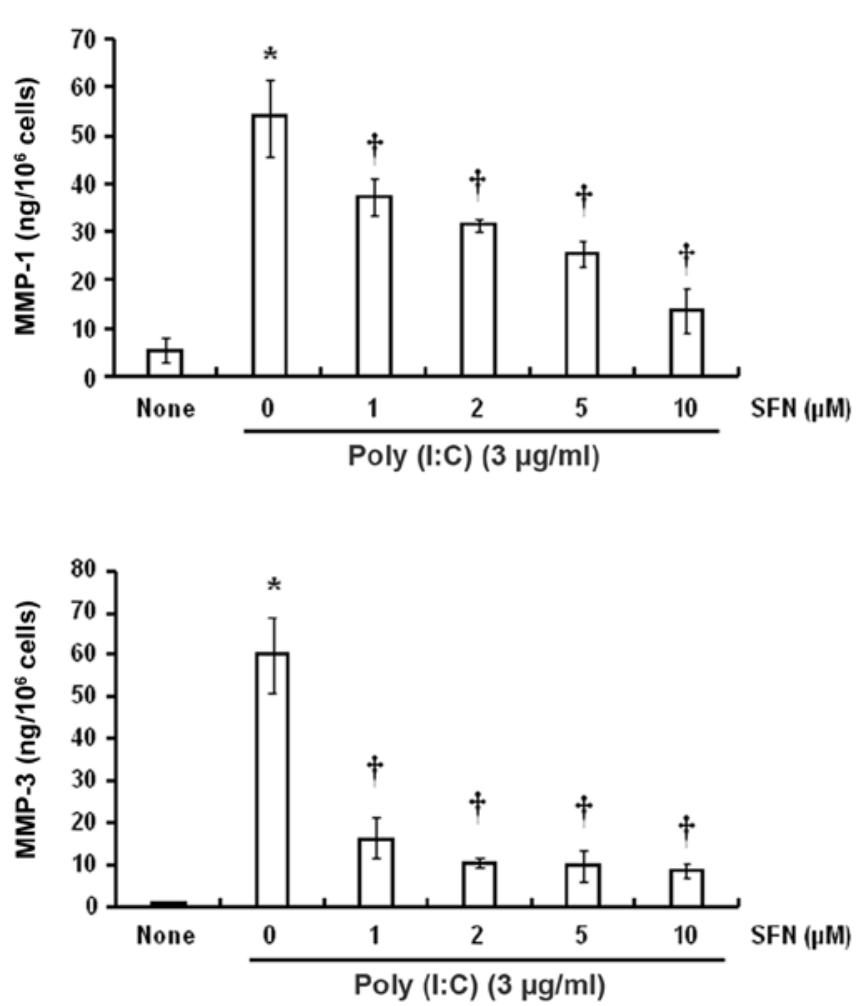
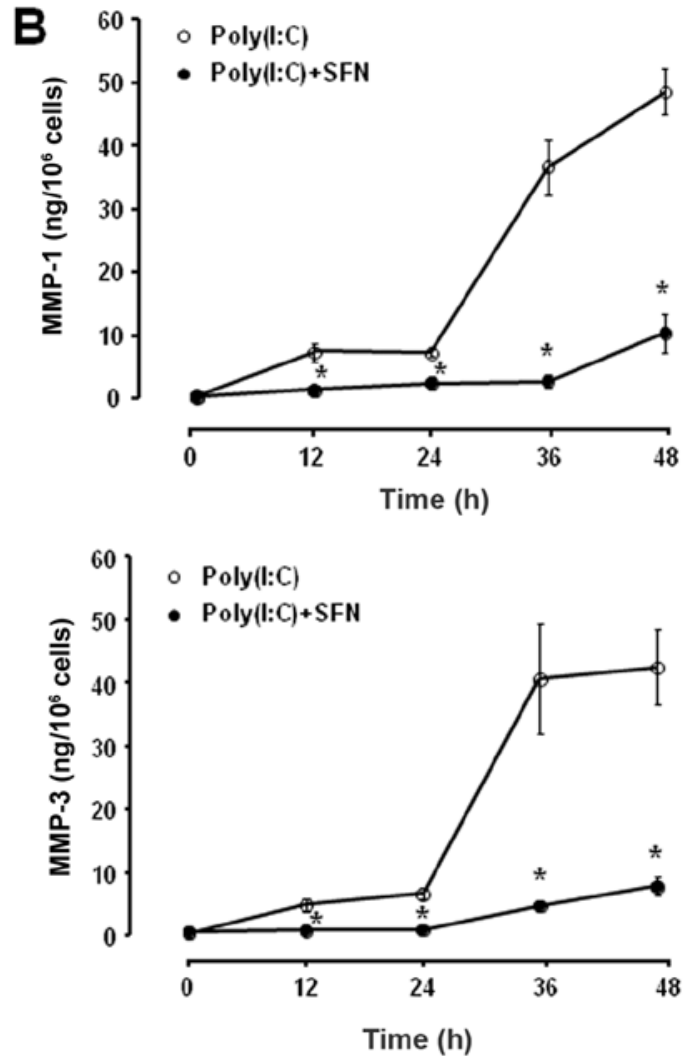

Figure 3. Inhibitory effects of SFN on the poly(I:C)-enhanced secretion of MMP-1 and MMP-3 by the HCFs. (A) Serum-deprived HCFs were incubated with the corresponding doses of SFN for $24 \mathrm{~h}$, then incubated with or without poly(I:C) ( $3 \mu \mathrm{g} / \mathrm{ml})$ for a further $48 \mathrm{~h}$. The measurement of MMP-1 and MMP-3 was determined using ELISA. " $\mathrm{P}<0.05$ compared with the control group (None); $\mathrm{P}<0.05$ compared with that in cells exposed to poly(I:C) alone. (B) Serum-deprived HCFs were treated with SFN $[10 \mu \mathrm{M}$ (solid circles)] or without [0 $\mu \mathrm{M}$ (open circles)] for $24 \mathrm{~h}$, then incubated for the specified time points with poly(I:C) $(3 \mu \mathrm{g} / \mathrm{ml})$, following which the culture supernatants were analyzed using ELISA. * $\mathrm{P}<0.05$ compared with the respective times in the group with poly(I:C) alone. SFN, sulforaphane; poly(I:C), polyinosinic-polycytidylic acid; HCF, human corneal fibroblasts; MMP, matrix metalloproteinases.

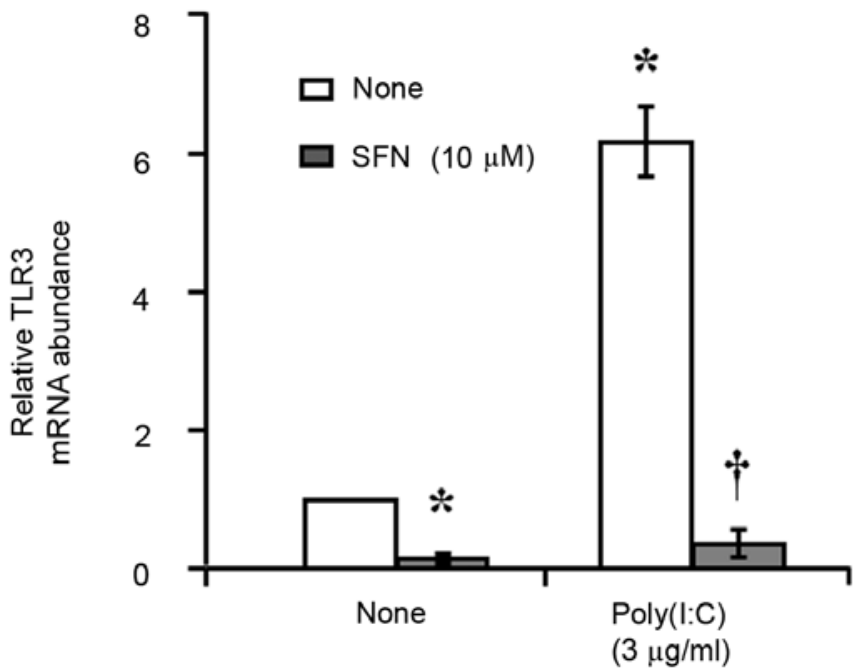

Figure 4. Inhibitory effect of SFN on the poly(I:C)-induced upregulation of TLR3 mRNA expression level in the HCFs. Serum-deprived HCFs were incubated first for $24 \mathrm{~h}$ in the absence or presence of SFN $(10 \mu \mathrm{M})$, then for an additional $4 \mathrm{~h}$ in the absence or presence of poly(I:C) $(3 \mu \mathrm{g} / \mathrm{ml})$. The TLR3 mRNA expression level in the cells was determined using reverse transcription-quantitative PCR analysis. The data are presented as the mean \pm SD from 3 replicates, from 3 independent experiments. ${ }^{*} \mathrm{P}<0.05$ compared with that in cells incubated without treatment; ${ }^{\dagger} \mathrm{P}<0.05$ compared with that in cells exposed to poly(I:C) alone. SFN, sulforaphane; poly(I:C), polyinosinicpolycytidylic acid; TLR, Toll-like receptor; HCF, human corneal fibroblasts. attenuated the activation of $\mathrm{NF}-\kappa \mathrm{B}$ signaling induced by poly(I:C) in HCFs.

Effect of SFN on the activation of AKT associated with poly $(I: C)$ in HCFs. Finally, the effect of SFN on the activation of the phosphoinositide 3-kinase (PI3K)-Akt signaling pathway was investigated with poly(I:C) in HCFs. Western blot analysis showed that the phosphorylation of Akt induced by exposure of HCFs to poly(I:C) for 30 min was inhibited by SFN (10 $\mu \mathrm{M}$; Fig. 7).

\section{Discussion}

Viral stromal keratitis is not only an infectious disease but also a chronic immunopathological condition (1). Viral stromal keratitis was found to upregulate the mRNA expression of TLR3 and subsequent production of various cytokines and chemokines, such as IL-6, IL-8 and MCP-1, in corneal fibroblasts (32). Poly(I:C), an analogue of the viral dsRNA, was found to activate TLR3 and has been adopted as an experimental tool to model the effects of HSV-1 infection $(10,12,13)$. The cytokines, IL- 8 and IL- 6 and the chemokine, MCP- 1 have key roles in the inflammatory response, by attracting neutrophils, monocytes and macrophages (17-19). SFN reportedly inhibited the release of IL-6 induced by lipopolysaccharide in microglial cells (26) in a rat model of endometriosis (24), 
A

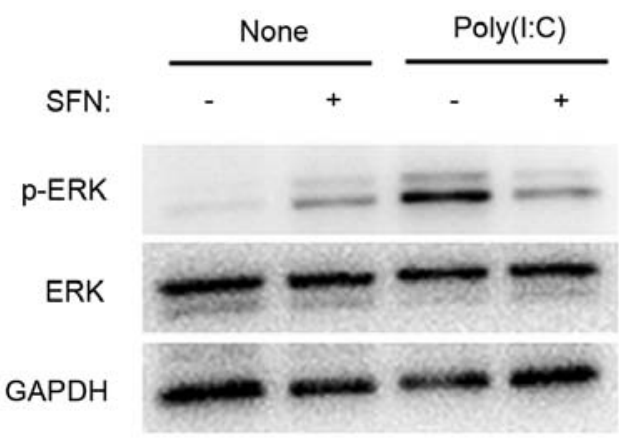

C

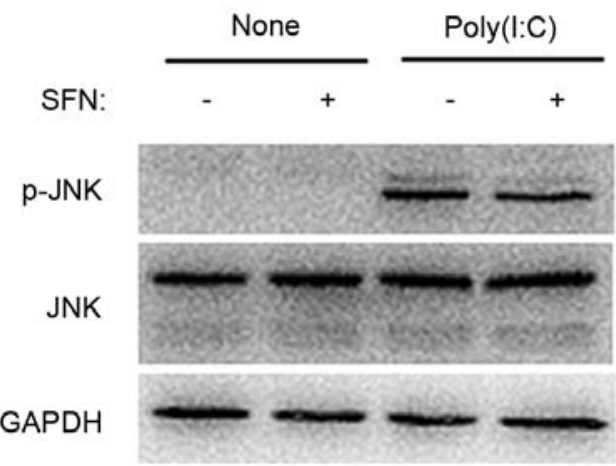

B

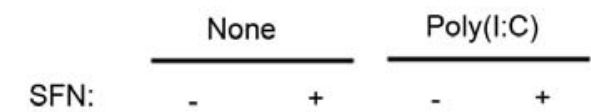

$\mathrm{p}-\mathrm{p} 38$

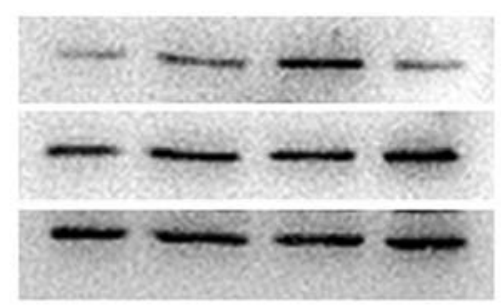

GAPDH

D

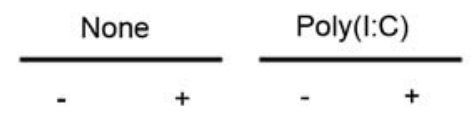

p-c-Jun

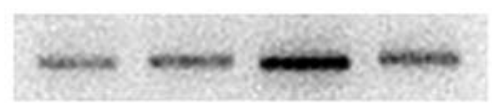

c-Jun

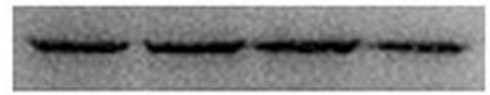

GAPDH

Figure 5. Effects of SFN on the poly(I:C)-associated activation of the MAPK and AP-1 signaling pathway in the HCFs. Serum-deprived HCFs were incubated first for $24 \mathrm{~h}$ with or without SFN (10 and $0 \mu \mathrm{M})$, then for $90 \mathrm{~min}$ with or without poly(I:C) $(3 \mu \mathrm{g} / \mathrm{ml})$. The measurements of total or activated (A) ERK, (B) p38, (C) JNK and (D) c-Jun and GAPDH (loading control) were determined using western blot analysis. AP-1, activator protein-1; SFN, sulforaphane; p-, phosphorylated; poly(I:C), polyinosinic-polycytidylic acid; HCF, human corneal fibroblasts.

B

A
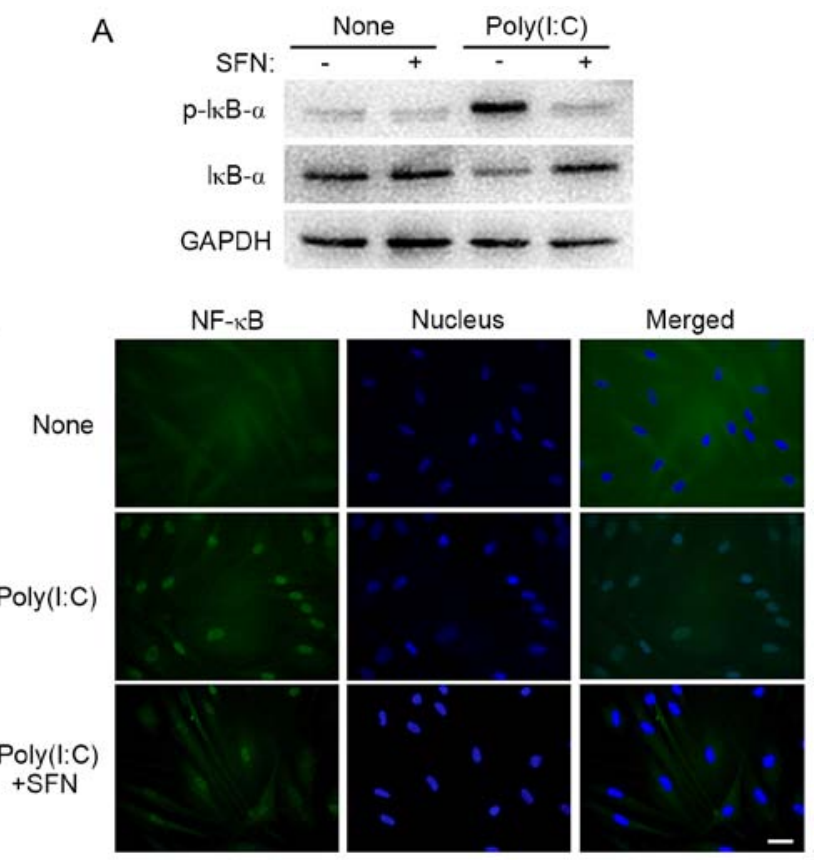

Figure 6. Effect of SFN on the poly(I:C)-associated activation of NF-kB signaling in the HCFs. Serum-deprived HCFs were incubated first for $24 \mathrm{~h}$ with or without SFN $(10$ and $0 \mu \mathrm{M})$ and incubated for an additional 90 min

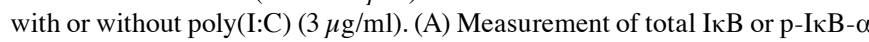
and GAPDH (loading control) protein expression level determined using western blot analysis. (B) Cells were examined using immunofluorescence staining with NF- $\mathrm{kB}$ p65 antibodies (green fluorescence) and for nuclear staining with DAPI (blue fluorescence). Scale bar, $50 \mu \mathrm{m}$. SFN, sulforaphane; poly(I:C), polyinosinic-polycytidylic acid; HCF, human corneal fibroblasts; p-, phosphorylated.

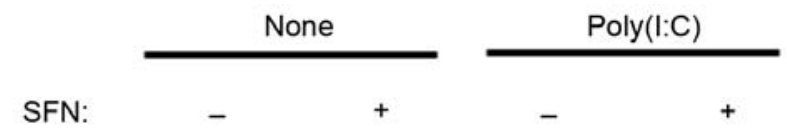

p-Akt

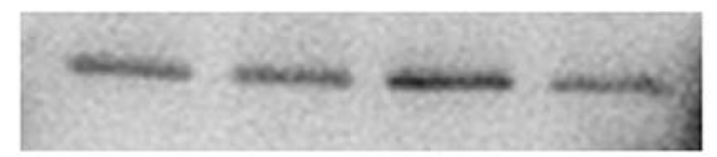

Akt

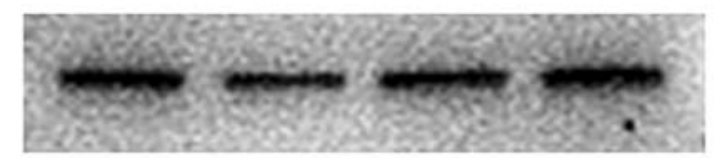

GAPDH

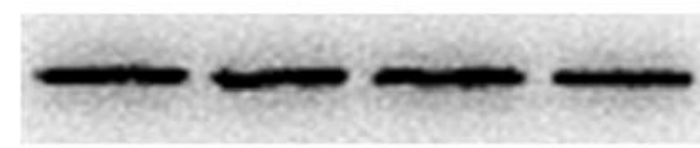

Figure 7. Effect of SFN on the poly(I:C)-associated activation of Akt signaling in HCFs. Serum-deprived HCFs were incubated for $24 \mathrm{~h}$ with or without SFN (10 and $0 \mu \mathrm{M})$ then for $30 \mathrm{~min}$ with or without poly(I:C) $(3 \mu \mathrm{g} / \mathrm{ml})$. The total or p-Akt protein expression level was determined using western blot analysis. SFN, sulforaphane; poly(I:C), polyinosinic-polycytidylic acid; HCF, human corneal fibroblasts; $\mathrm{p}$-, phosphorylated.

and in a mouse model of acute lung cancer (25). The present study found that SFN inhibited the poly(I:C)-induced production of IL-6, IL-8 and MCP-1 by HCFs. This suggested that SFN could be a promising drug candidate for therapeutic modulation of the inflammatory response in viral stromal keratitis. 
Viral stromal keratitis has been associated with the proteolytic degradation of stromal collagen, which can lead to corneal ulceration and ultimately, to the loss of corneal transparency (21). MMPs are zinc-dependent enzymes that degrade extracellular matrix proteins, of which MMP-1 and MMP-3 are two major types and significantly contribute to corneal ulcers (21). Upregulation of MMP-1 or MMP-3 expression has been associated with varicella zoster virus (33) and cytomegalovirus (34) infection. Expression of MMP-3 was also found elevated in the brain stem of HSV-1-infected mice (35). The protein expression of MMPs was induced in viral keratitis $(36,37)$ and contributed to tissue infiltration by polymorphonuclear leukocytes (38). These various observations indicated the important role of MMPs in the pathogenesis of disease associated with viral keratitis. Consistent with a previous study (39), the present study found that poly(I:C) induced the concentration of MMP-1 and MMP-3 in corneal fibroblasts. This suggested that cells associated with lesions of viral keratitis may contribute to remodeling of the extracellular matrix and consequently corneal ulceration by producing MMPs. In previous studies, SFN was shown to prevent the upregulation of MMP-1 induced by ultraviolet irradiation in the skin of mice (40), and inhibited the production of MMP-1 and MMP-3 stimulated by IL-1 $\beta$ in synovial fibroblasts associated with rheumatoid arthritis (41). In the present study, SFN was found to suppress the poly(I:C)-associated release of these two MMPs by HCFs. Further studies are required to determine the effect of SFN on viral corneal ulceration; however, these results indicated that this agent may prove an effective treatment for this condition.

TLRs contribute to the initiation and modulation of inflammation in the eye (30). Upregulation of TLR3 mRNA expression in the human cornea has been association with HSV-1 infection (15). TLR3 is a specific receptor for dsRNA and would not be expected to detect DNA derived from a DNA virus, such as HSV-1 (15). However, dsRNA is produced by most viruses during their replication cycle and is considered a molecular marker of viral infection (42). As a synthetic analog of viral dsRNA, poly(I:C) is recognized by TLR3 (43). The present study found that poly(I:C) upregulated the TLR3 mRNA expression level in HCFs and that SFN attenuated this effect. Thus, the inhibitory effects of SFN on cytokine, chemokine and MMP expression in HCFs, exposed to poly(I:C) may be mediated by attenuation of the TLR3 signaling pathway.

Stimulation of TLR3 initiates a cascade of intracellular signaling, including that mediated by MAPKs and PI3K-Akt, and results in the activation of NF- $\mathrm{BB}$ or AP-1 (14). All of these signaling pathways have been associated with inflammation, including that of the cornea $(13,16,44,45)$. NF- $\kappa \mathrm{B}$, a transcription factor, mediates the mRNA expression level of inflammation-related genes, including cytokines, chemokines and adhesion molecules (46). Under basal conditions, NF- $\kappa \mathrm{B}$ is bound to the inhibitor, I $\kappa \mathrm{B}$ in the cytoplasm (47). The phosphorylation of $\mathrm{I} \kappa \mathrm{B}$, induced by inflammatory stimuli, triggers its degradation and consequently transfers the active $\mathrm{NF}-\kappa \mathrm{B}$ to the nucleus, where NF- $\mathrm{B}$, in turn, activates the mRNA expression level of cytokines, chemokines and MMP-related genes $(13,16)$. The JNK, p38 MAPKs and ERK are important pathways in the regulation of various cell activities, such as cell proliferation, differentiation and migration, and are significantly associated with inflammation, innate immunity and apoptosis $(48,49)$. The activation of TLRs by components of pathogens induces the phosphorylation of MAPKs, which can then lead to $\mathrm{I} \kappa \mathrm{B}$ phosphorylation and activation of $\mathrm{NF}-\kappa \mathrm{B}$ (50). The transcription factor, AP-1, also mediates the mRNA expression level of inflammatory genes (51). Activation of the AP-1 component c-Jun triggers the release of inflammatory mediators, and MMPs in human synoviocytes (45). It has been shown that the activation of the PI3K-Akt signaling pathway was associated with the regulation of MCP-1 mRNA and protein expression in human retinal pigment epithelial cells (52). Poly(I:C) was confirmed to induce the activation of Akt in HCFs (44). In the present study, SFN was demonstrated to inhibit the poly(I:C)-induced activation of ERK, p38, c-Jun and AKT, and the degradation of I $\mathrm{B}-\alpha$ and the nuclear translocation of NF- $\kappa \mathrm{B}$ in HCFs. This suggested that the anti-inflammatory effects of SFN in these cells may be mediated by the attenuation of signaling by the MAPK, AP-1, PI3K-Akt and NF- $\kappa \mathrm{B}$ pathways.

In conclusion, the present study showed that SFN inhibited the poly(I:C)-associated release of proinflammatory cytokines, chemokines and MMPs in HCFs, potentially through suppression of the TLR3, MAPK (ERK and p38), NF- $\mathrm{B}, \mathrm{AP}-1$ and Akt signaling pathways. SFN may be a potential treatment for corneal viral infection by limiting immune cell infiltration. Further research is warranted to investigate the potential efficacy of SFN for the treatment of viral stromal keratitis.

\section{Acknowledgements}

Not applicable.

\section{Funding}

This research was supported by the National Science Foundation of China (grant no. 81770889), the Natural Science Foundation of Guangdong Province (grant no. 2017A030313774), and from the Natural Science Foundation of Guangdong Province (grant no. 2018 A030313428).

\section{Availability of data and materials}

The datasets used and/or analyzed during the current study are available from the corresponding author on reasonable request.

\section{Authors' contributions}

YaL, YeL and XZha contributed to the study design. PL, HZ and LC performed the experiments. PL, XZhe and XY analyzed the data. XZhe and YaL wrote the first draft of the manuscript. All authors read and approved the final manuscript.

\section{Ethics approval and consent to participate}

Not applicable.

\section{Patient consent for publication}

Not applicable. 


\section{Competing interests}

The authors declare that they have no competing interests.

\section{References}

1. Rowe AM, St Leger AJ, Jeon S, Dhaliwal DK, Knickelbein JE and Hendricks RL: Herpes keratitis. Prog Retin Eye Res 32: 88-101, 2013

2. Farooq AV and Shukla D: Herpes simplex epithelial and stromal keratitis: An epidemiologic update. Surv Ophthalmol 57: 448-462, 2012

3. Reynaud C, Rousseau A, Kaswin G, M'Garrech M, Barreau E and Labetoulle M: Persistent impairment of quality of life in patients with herpes simplex keratitis. Ophthalmology 124 160-169, 2017.

4. Biswas PS and Rouse BT: Early events in HSV keratitis-setting the stage for a blinding disease. Microbes Infect 7: 799-810, 2005

5. Knickelbein JE, Hendricks RL and Charukamnoetkanok P: Management of herpes simplex virus stromal keratitis: An evidence-based review. Surv Ophthalmol 54: 226-234, 2009.

6. Urtti A: Challenges and obstacles of ocular pharmacokinetics and drug delivery. Adv Drug Deliv Rev 58: 1131-1135, 2006.

7. DelMonte DW and Kim T: Anatomy and physiology of the cornea. J Cataract Refract Surg 37: 588-598, 2011.

8. Smith RS, Smith TJ, Blieden TM and Phipps RP: Fibroblasts as sentinel cells. Synthesis of chemokines and regulation of inflammation. Am J Pathol 151: 317-322, 1997.

9. Xi X, McMillan DH, Lehmann GM, Sime PJ, Libby RT, Huxlin KR, Feldon SE and Phipps RP: Ocular fibroblast diversity: Implications for inflammation and ocular wound healing. Invest Ophthalmol Vis Sci 52: 4859-4865, 2011.

10. Lee G, Park JS, Lee EJ, Ahn JH and Kim HS: Anti-inflammatory and antioxidant mechanisms of urolithin $B$ in activated microglia Phytomedicine 55: 50-57, 2019.

11. Guan X, Zhang M, Fu M, Luo S and Hu Q: Herpes simplex virus type 2 immediate early protein ICP27 inhibits IFN-beta production in mucosal epithelial cells by antagonizing IRF3 activation. Front Immunol 10: 290, 2019.

12. Herbert C, Zeng QX, Shanmugasundaram R, Garthwaite L, Oliver BG and Kumar RK: Response of airway epithelial cells to double-stranded RNA in an allergic environment. Transl Respir Med 2: 11, 2014

13. Liu Y, Kimura K, Yanai R, Chikama T and Nishida T: Cytokine, chemokine, and adhesion molecule expression mediated by MAPKs in human corneal fibroblasts exposed to poly(I:C) Invest Ophthalmol Vis Sci 49: 3336-3344, 2008.

14. Garrington TP and Johnson GL: Organization and regulation of mitogen-activated protein kinase signaling pathways. Curr Opin Cell Biol 11: 211-218, 1999.

15. Matsumoto M, Funami K, Oshiumi H and Seya T: Toll-like receptor 3: A link between toll-like receptor, interferon and viruses. Microbiol Immunol 48: 147-154, 2004.

16. Kimura K, Orita T, Kondo Y,Zhou H and Nishida T: Upregulation of matrix metalloproteinase expression by poly(I:C) in corneal fibroblasts: Role of NF- $\mathrm{BB}$ and interleukin-1 $\beta$. Invest Ophthalmol Vis Sci 51: 5012-5018, 2010.

17. Bazzoni F, Cassatella MA, Rossi F, Ceska M, Dewald B and Baggiolini M: Phagocytosing neutrophils produce and release high amounts of the neutrophil-activating peptide 1/interleukin 8 . J Exp Med 173: 771-774, 1991.

18. Bianconi V, Sahebkar A, Atkin SL and Pirro M: The regulation and importance of monocyte chemoattractant protein-1. Curr Opin Hematol 25: 44-51, 2018

19. Scheller J, Chalaris A, Schmidt-Arras D and Rose-John S: The pro- and anti-inflammatory properties of the cytokine interleukin-6. Biochim Biophys Acta 1813: 878-888, 2011.

20. Thomas J, Kanangat S and Rouse BT: Herpes simplex virus replication-induced expression of chemokines and proinflammatory cytokines in the eye: Implications in herpetic stromal keratitis. J Interferon Cytokine Res 18: 681-690, 1998.

21. Fini ME, Cook JR and Mohan R: Proteolytic mechanisms in corneal ulceration and repair. Arch Dermatol Res 290 (Suppl): S12-S23, 1998

22. Matusheski NV, Juvik JA and Jeffery EH: Heating decreases epithiospecifier protein activity and increases sulforaphane formation in broccoli. Phytochemistry 65: 1273-1281, 2004.
23. Lenzi M, Fimognari $\mathrm{C}$ and Hrelia P: Sulforaphane as a promising molecule for fighting cancer. Cancer Treat Res 159: 207-223, 2014.

24. Zhou A, Hong Y and Lv Y: Sulforaphane attenuates endometriosis in rat models through inhibiting PI3K/Akt signaling pathway. Dose Response 17: 1559325819855538, 2019.

25. Qi T, Xu F, Yan X, Li S and Li H: Sulforaphane exerts anti-inflammatory effects against lipopolysaccharide-induced acute lung injury in mice through the Nrf2/ARE pathway. Int J Mol Med 37: 182-188, 2016.

26. Qin S, Yang C, Huang W, Du S, Mai H, Xiao J and Lü T: Sulforaphane attenuates microglia-mediated neuronal necroptosis through down-regulation of MAPK/NF- $\kappa \mathrm{B}$ signaling pathways in LPS-activated BV-2 microglia. Pharmacol Res 133 218-235, 2018.

27. Liu H, Smith AJO, Lott MC, Bao Y, Bowater RP, Reddan JR and Wormstone IM: Sulforaphane can protect lens cells against oxidative stress: Implications for cataract prevention. Invest Ophthalmol Vis Sci 54: 5236-5248, 2013

28. Dulull NK, Dias DA, Thrimawithana TR and Kwa FAA: L-sulforaphane confers protection against oxidative stress in an in vitro model of age-related macular degeneration. Curr Mol Pharmacol 11: 237-253, 2018.

29. Ziaei A, Schmedt T, Chen Y and Jurkunas UV: Sulforaphane decreases endothelial cell apoptosis in fuchs endothelial corneal dystrophy: A novel treatment. Invest Ophthalmol Vis Sci 54: 6724-6734, 2013

30. Erdinest N, Aviel G, Moallem E, Anteby I, Yahalom C, Mechoulam H, Ovadia $\mathrm{H}$ and Solomon A: Expression and activation of toll-like receptor 3 and toll-like receptor 4 on human corneal epithelial and conjunctival fibroblasts. J Inflamm (Lond) 11: 3, 2014.

31. Livak KJ and Schmittgen TD: Analysis of relative gene expression data using real-time quantitative PCR and the 2(-Delta Delta C(T)) method. Methods 25: 402-408, 2001

32. Jin X, Qin Q, Chen W and Qu J: Expression of toll-like receptors in the healthy and herpes simplex virus-infected cornea. Cornea 26: 847-852, 2007.

33. Nagel MA, Choe A, Rempel A, Wyborny A, Stenmark K and Gilden D: Differential regulation of matrix metalloproteinases in varicella zoster virus-infected human brain vascular adventitial fibroblasts. J Neurol Sci 358: 444-446, 2015.

34. Prochnau D, Lehmann M, Straube E, Figulla HR and Rödel J: Human cytomegalovirus induces MMP-1 and MMP-3 expression in aortic smooth muscle cells. Acta Microbiol Immunol Hung 58: 303-317, 2011

35. Caignard G, Leiva-Torres GA, Leney-Greene M, Charbonneau B, Dumaine A, Fodil-Cornu N, Pyzik M, Cingolani P, Schwartzentruber J, Dupaul-Chicoine J, et al: Genome-wide mouse mutagenesis reveals CD45-mediated T cell function as critical in protective immunity to HSV-1. PLoS Pathog 9: e1003637, 2013.

36. Yang YN, Bauer D, Wasmuth S, Steuhl KP and Heiligenhaus A: Matrix metalloproteinases (MMP-2 and 9) and tissue inhibitors of matrix metalloproteinases (TIMP-1 and 2) during the course of experimental necrotizing herpetic keratitis. Exp Eye Res 77: 227-237, 2003.

37. Heiligenhaus A, Li HF, Yang Y, Wasmuth S, Steuhl KP and Bauer D: Transplantation of amniotic membrane in murine herpes stromal keratitis modulates matrix metalloproteinases in the cornea. Invest Ophthalmol Vis Sci 46: 4079-4085, 2005.

38. Wiegand C, Schönfelder U, Abel M, Ruth P, Kaatz M and Hipler UC: Protease and pro-inflammatory cytokine concentrations are elevated in chronic compared to acute wounds and can be modulated by collagen type I in vitro. Arch Dermatol Res 302: 419-428, 2010

39. Kimura K, Nomi N, Yan ZH, Orita T and Nishida T: Inhibition of poly(I:C)-induced matrix metalloproteinase expression in human corneal fibroblasts by triptolide. Mol Vis 17: 526-532, 2011.

40. Chaiprasongsuk A, Lohakul J, Soontrapa K, Sampattavanich S, Akarasereenont $\mathrm{P}$ and Panich U: Activation of Nrf2 reduces UVA-mediated MMP-1 upregulation via MAPK/AP-1 signaling cascades: The photoprotective effects of sulforaphane and hispidulin. J Pharmacol Exp Ther 360: 388-398, 2017.

41. Choi YJ, Lee WS, Lee EG, Sung MS and Yoo WH: Sulforaphane inhibits IL-1 $\beta$-induced proliferation of rheumatoid arthritis synovial fibroblasts and the production of MMPs, COX-2, and PGE2. Inflammation 37: 1496-1503, 2014.

42. Meylan E and Tschopp J: Toll-like receptors and RNA helicases: Two parallel ways to trigger antiviral responses. Mol Cell 22: $561-569,2006$. 
43. Takeuchi $\mathrm{O}$ and Akira S: Toll-like receptors; their physiological role and signal transduction system. Int Immunopharmacol 1: 625-635, 2001

44. Orita T, Kimura K, Zhou HY and Nishida T: Poly(I:C)-induced adhesion molecule expression mediated by NF-\{kappa\}B and phosphoinositide 3-kinase-Akt signaling pathways in human corneal fibroblasts. Invest Ophthalmol Vis Sci 51: 5556-5560, 2010.

45. Sweeney SE, Kimbler TB and Firestein GS: Synoviocyte innate immune responses: II. Pivotal role of IFN regulatory factor 3 . J Immunol 184: 7162-7168, 2010.

46. Lawrence T: The nuclear factor NF-kappaB pathway in inflammation. Cold Spring Harb Perspect Biol 1: a001651, 2009.

47. Hayden MS and Ghosh S: Shared principles in NF-kappaB signaling. Cell 132: 344-362, 2008.
48. Sun Y, Liu WZ, Liu T, Feng X, Yang N and Zhou HF: Signaling pathway of MAPK/ERK in cell proliferation, differentiation, migration, senescence and apoptosis. J Recept Signal Transduct Res 35: 600-604, 2015.

49. Arthur JS and Ley SC: Mitogen-activated protein kinases in innate immunity. Nat Rev Immunol 13: 679-692, 2013.

50. Hoesel B and Schmid JA: The complexity of NF- $\mathrm{kB}$ signaling in inflammation and cancer. Mol Cancer 12: 86, 2013.

51. Trop-Steinberg S and Azar Y: AP-1 expression and its clinical relevance in immune disorders and cancer. Am J Med Sci 353: 474-483, 2017.

52. Bian ZM, Elner SG, Yoshida A and Elner VM: Differential involvement of phosphoinositide 3-kinase/Akt in human RPE MCP-1 and IL-8 expression. Invest Ophthalmol Vis Sci 45: 1887-1896, 2004. 